\title{
Techno-economic and sensitivity analysis for grid-connected renewable energy electric boat charging station in Terengganu
}

\author{
N. A. S. Salleh ${ }^{1, *}$ and W. M. W. Muda ${ }^{1,2}$ \\ ${ }^{1}$ School of Ocean Engineering, University Malaysia Terengganu \\ ${ }^{2}$ Special Interest Group of Eastern Corridor Renewable Energy
}

\begin{abstract}
In order to encourage the eco-friendly technologies in transportation sector, the reliance on fuel need to be reduced and the use of renewable energy (RE) technology as energy source are widely explored by researchers. Thus, this study focus on the feasibility of developing gridconnected renewable energy electric boat charging station for the fishermen in Terengganu using simulation-based method by HOMER software. Five year solar radiation and wind speed data were collected at Universiti Sultan Zainal Abidin (UNISZA) weather station. For load profile, the information about fishing activities and the amount of subsidy spent by the government were obtained from the interview session with the fishermen and validated with Lembaga Kemajuan Ikan Malaysia (LKIM). The results acquired are compared between grid-only and grid-connected RE systems in term of net present cost (NPC), operational cost and payback period. A sensitivity analysis is done to find the minimal Feed-in Tariff (FiT) rate that can be implemented in order to encourage the use of RE system in this sector. Then, the relationship between FiT and NPC, payback period and emission of pollutants are analyzed. At current FiT rates RM $0.813 / \mathrm{kWh}$, hybrid grid-PV system manages to achieve its optimal in generating high income from selling the power to the grid with convincing amount of electricity production and short payback period. It is concluded at minimum RM $0.56 / \mathrm{kWh}$ of FiT, the grid-connected RE system is possible to be developed because its performance shows better outcome compared to the grid-only system.
\end{abstract}

\section{Introduction}

The heavy dependency on fuels by conventional boat (CB) to generate the motor normally affecting the water ecosystem [1]. The engine cooling water and waste water contains oils and fuel residue which is pumped out into the sea causing negative impacts to underwater organism. Besides the harmful waste, $\mathrm{CB}$ also emit exhaust gases and noise pollution from the engine $[2,3]$. Similar to other electric vehicle, electric boat (EB) can be

\footnotetext{
Corresponding author: gsk2357@pps.umt.edu.my
} 
used to replace the use of $\mathrm{CB}$ in reducing the abovementioned problems. Inspired by the rapid growth of electric vehicles nowadays, EB is widely used in a few countries such as Australia and Canada [4]. According to Minami [5], the use of electric motor gives a lots of advantages in fishing activities such as quietness, less vibration and lack of toxic during fishing. The reliance on fuel is replaced with battery which is needed to be charged by directly connected to the grid. However, if the charging demand is not well-controlled, it can damage the grid [6]. Therefore, the encouragement to use renewable energy (RE) in operating grid-connected charging station need to be proposed to control the dependency on grid [7].

As Malaysia is a tropical climate country, the potential to exploit RE technologies is high. Malaysia shows high solar power generation with approximately $4000-5000 \mathrm{Wh} / \mathrm{m}^{2}$ of daily average solar radiation [8,9]. Terengganu has been identified with the capability to generate wind power electricity [10]. With possible amount of solar irradiance and wind speed, Terengganu is one of high potential states in developing RE technology. Unfortunately, statistics from Sustainable Energy Development Authority (SEDA) shows that Terengganu is still far behind compared to western region in implementing this technology [11].

Kuala Terengganu faces the South China Sea which makes fisheries sector is one of important source of economic development. Results from interview session with LKIM Chendering officer, a total amount RM 1,228,325.70 of fuel subsidy was spent by the government in 2014 for 242 fishermen in Kuala Terengganu Utara area [12]. Other than that, fishermen also accepting numbers of incentive such as "e-Dana", "e-kasih", and monthly allowance to accommodate the needs on fuel. But with high cost of living and uncertain oil rates nowadays, the distribution of subsidies for the fisherman is still not enough. Mentioned by Hayati in [13], most of the fishermen are poor. Thus, solutions are needed to help them out with these struggles.

Over the years, few energy policies and programs have been introduced by the government to encourage the use of RE power application in industries, community and individuals sector. The government began to drawing up initiatives in RE field since 1996 in the 7th Malaysia Plan (7MP). Since then, the next Malaysia Plan covering the areas of RE up to now in the 10th Malaysia Plan (10MP) [14]. New targets and goals constantly introduced to improve the quality control and energy management in Malaysia. Regarding to this effort, government introduced Feed-in Tariff (FiT) scheme which the implementation is managed by SEDA in $10 \mathrm{MP}$ where the RE system installation is accessed to the TNB's grid and setting a favorable price per unit of RE sold $[11,15,16]$.

Researchers, for example in $[9,17,18]$ are already striving to minimize the gap in terms of power system technology development in Terengganu from the rural to the urban areas. The progress from literatures can be seen that Terengganu has its own potential to be successful in generating power from renewable energy. However, statistics of the development for renewable energy technology in Peninsular Malaysia are quite slow [11]. Therefore, due to big investment cost involved to develop RE technology [19], economic analyses on the proposed system need to be highlighted.

This paper also is an extension of the proceeding "Feasibility Study of Optimization and Economic Analysis for Grid-connected Renewable Energy Electric Boat Charging Station in Kuala Terengganu" [20]. In [20], FiT rate RM 1.49/kWh obtained from [21] was used to conduct the optimization and simulation in HOMER to analyze the cost-benefit of the system. However in this paper, the current FiT rate (for January 2015) which is RM0.813/kWh (include the bonus) is used. Since the FiT rates keep decreasing every year, the sensitivity analysis is also done to find the minimal FiT rates for the proposed system in gaining profitable revenue in RE technologies. 


\section{Hybrid system configurations}

Renewable energy components i.e. PV modules and wind turbine are combined with nonrenewable components which is the grid in HOMER to produce a hybrid renewable energy system. Fig 1 shows the configuration of grid-connected RE charging station in HOMER. The load represented in this system is battery for EB which is needed to be charged by the hybrid renewable energy charging station. Since the proposed system is a grid-connected system, when electrical production is insufficient, energy are purchased from the grid. But, if there is excess electricity, it is sold to the grid by following FiT scheme which is fixed by SEDA. The HOMER software is used in this study to determine the optimal configuration based on the optimization, simulation and sensitivity analysis.

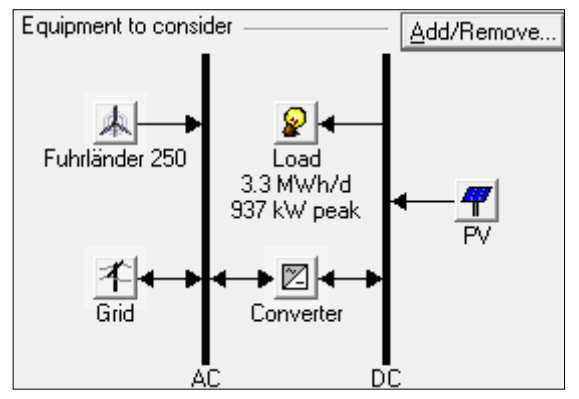

Fig. 1. Configuration of grid-connected hybrid RE system in HOMER.

Kuala Terengganu Utara (KTU) is selected as a case study area with latitude and longitude are 5.31 and 103.12 respectively [9]. The cost and specification for each component used in the configuration such as the PV module, wind turbine, converter and grid are needed to calculate the feasible cost of system configuration. Some input parameters are also required such as solar radiation inputs $\left(\mathrm{kWh} / \mathrm{m}^{2} /\right.$ day), wind speed $(\mathrm{m} / \mathrm{s})$ and load profile $(\mathrm{kW})$ as daily usage of power by the load.

\subsection{Profile load/ load demand}

Similar to [20], the information on fisheries activities of 16 out of 242 fishermen were obtained by doing interview session. Then, the data was validated with LKIM Chendering [12] by conducting a short dialogue session. In addition, LKIM is providing information on the annual amount of fuel subsidy and government incentive for 2014. Summarization of data can be seen in Table 1 of [20].

Approximately, $45 \mathrm{~kW}$ of electric motor is needed for EB to replace $60 \mathrm{hp}$ engine power from conventional boat. Inspired by [5], a $20 \mathrm{kWh} \mathrm{Li-ion} \mathrm{battery} \mathrm{is} \mathrm{chosen} \mathrm{to} \mathrm{function} \mathrm{as}$ electrical supplier for the electric motor. The operating hours to charge the EB is from 2:00 p.m. to 12:00 a.m. To make a convenience charging station for all the fishermen in KTU, 25 units of charging station are needed. Assuming 25 units of charging station are operating simultaneously in charging $20 \mathrm{kWh}$ loads, thus, the charging demand of the load in a day for the system is $500 \mathrm{~kW}$ for 10 hours after the working hours. Fig 2 shows the load profile of the proposed system. 


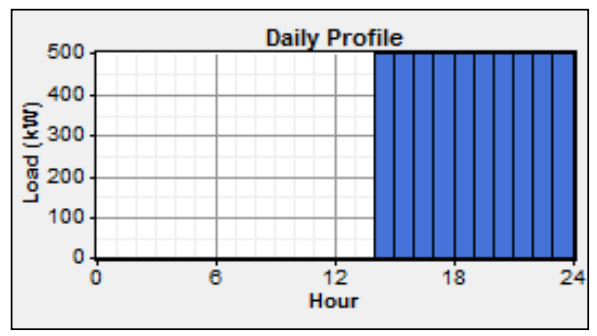

Fig. 2. Load profile of March - October.

The load profile starts to be at peak after 2:00 p.m. as the fisherman are home from their fisheries activities to recharge their battery boat. But, during the Northeast Monsoon from November to February, the load profile becomes null because the fishermen not be able to go out for fishing. There is no charging activities occur for four months. This explains the average electricity used by the load is $3.3 \mathrm{MWh} /$ day, as calculated by HOMER.

\subsection{Renewable energy resources}

Solar radiation data was collected from UNISZA weather station at Kuala Terengganu [22]. Fig 3 illustrates a plotted annual solar radiation and the clearness index of case study area calculated by HOMER with the following daily radiation data entered. The range of solar radiation is from $2.493 \mathrm{kWh} / \mathrm{m}^{2} /$ day to $6.447 \mathrm{kWh} / \mathrm{m}^{2} /$ day and the average of solar radiation is $4.472 \mathrm{kWh} / \mathrm{m}^{2} /$ day. According to Fig 3, the solar irradiance from March to October is high; meanwhile it is low from November to February due to Northeast Monsoon season.

Fig 4 shows the average monthly wind speed data measured at $25 \mathrm{~m}$ above the sea level. The average wind speed ranges from $2.174 \mathrm{~m} / \mathrm{s}$ to $4.175 \mathrm{~m} / \mathrm{s}$ with an annual average of $2.605 \mathrm{~m} / \mathrm{s}$. the highest wind shown to occur in December - February, because of the Monsoon season. The wind speeds over the year; a Weibull parameter $(k)$ is assumed 2.00 and represented in Fig 5 with autocorrelation factor of 0.85 . It is measured based on hourto-hour randomness of wind speed [23].

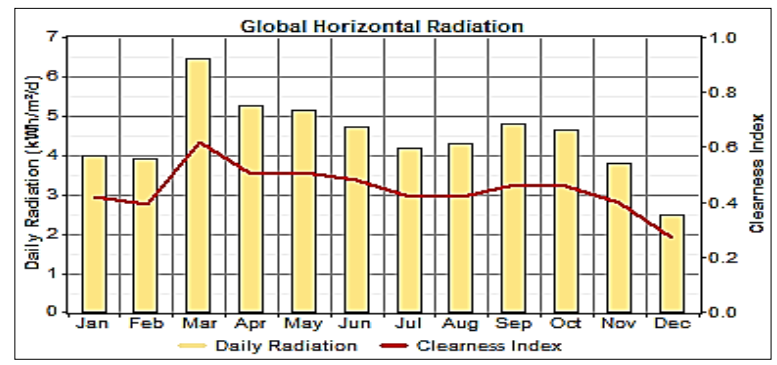

Fig. 3. The annual solar radiation and clearness index of Kuala Terengganu. 


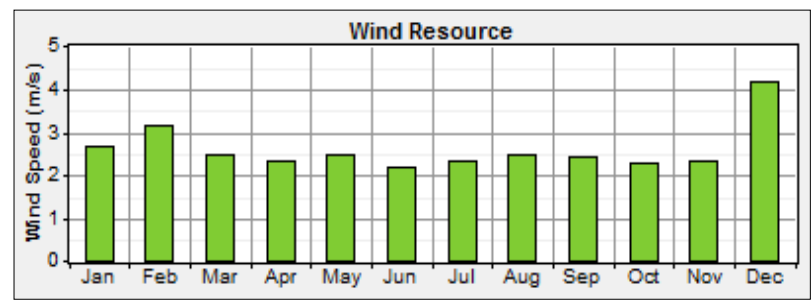

Fig. 4. Monthly average wind speed data.

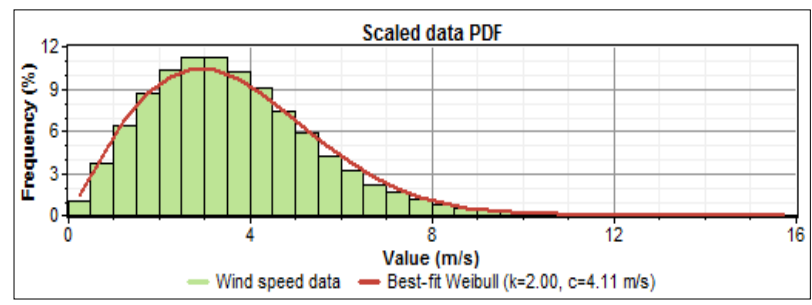

Fig. 5. Weibull probability function of wind speed.

\subsection{Hybrid system component assessments}

In a power system, a component generates, delivers and converts energy to feed the needs of the system. Thus, in this system, PV module, wind turbine and converter are selected to fill the requirement of charging station. Compared to [20], battery was not included in the configuration because it contributes to high NPC. Moreover, the system done well without battery storage because any excess electricity generated by RE sources can be sold directly to the grid which is more cost-effective than store it in the battery. Specifications of the components can be referred to [20].

\subsubsection{Grid utility and feed-in tariff (FiT)}

This project uses the Tariff C1; Medium Voltage General Commercial Tariff [24] with the commercial rate and maximum demand are RM $0.365 / \mathrm{kWh}$ and RM 30.30/kW/month, respectively. By referring [11] for January 2015, the FiT rate for solar PV with a capacity $1 \mathrm{MW}$ to $10 \mathrm{MW}$ is RM 0.547 . For the bonus FiT rates, the proposed system eligible to receive RM 0.166 as it is used as building materials. The PV modules are installed at the rooftop of the boat dock. In addition, PV module and converter was assembled locally for grid compatibility in Malaysia. Thus, additional RM 0.050 included for each bonus criteria. Therefore, the summation of basic rates and bonus rate in 2015 made the FiT rate for gridconnected solar PV is set at RM $0.813 / \mathrm{kWh}$. In addition, the purchase capacity from the grid is set up to $5000 \mathrm{~kW}$ and sale capacity from the grid is set to $1000 \mathrm{~kW}$ only. This is due to the fact that the amount of electricity sold to grid should not exceed the maximum capacity used by load to prevent the effect of reverse power flow [25].

\section{System analyses}

A few analyses on grid-connected RE hybrid system in term of economic feasibility are carried out based on net present cost (NPC), operating cost and payback period from optimization results obtained in HOMER. Comparison between investment cost of 
developing the charging station and fuel subsidy given by the government are also highlighted in this study.

\subsection{Net present cost (NPC)}

The NPC assesses all the cost throughout 25 years system lifetime including the initial costs, replacement costs, operation and maintenance $(\mathrm{O} \& \mathrm{M})$ and grid rate costs. Total NPC is calculated using the Eq. (1) to Eq. (3) from [21]. Department of Statistics Malaysia in $[26,27]$ reported the inflation rate of 2015 in Malaysia is $0.90 \%$ and the nominal interest rate is $3.25 \%$. Therefore, the annual real interest rate is $2.33 \%$.

$$
\begin{aligned}
N P C & =\frac{C_{\text {ann }, \text { tot }}}{\operatorname{CRF(i,N)}} \\
C R F(i, N) & =\frac{i(1+i)^{N}}{(1+i)^{N}-1} \\
i & =\frac{i^{\prime}-f}{1+f}
\end{aligned}
$$

\subsection{Operating cost}

The annual O\&M, annualized replacement cost minus the annualized salvage value and net grid purchases are included in total operating cost of the system. The salvage value is the cost of remaining in a component at the end of project lifetime. Meanwhile, the net grid purchases are obtained from grid purchases minus grid sales.

\subsection{Payback period}

The Payback Period indicates the length of time for a project to generate enough cash flow to pay back the initial investment. Payback period is the ratio of the extra first cost, $\Delta \mathrm{P}$, to the annual savings, S, as in equation (4) [28].

$$
\text { Payback period }=\frac{\text { Extra first cost }, \Delta P(\$)}{\text { Annual saving, } S(\$ / y r)}
$$

\section{Results and discussion}

All possible configurations of components are obtained from optimization result in HOMER. The orders of configurations are ranked based on the NPC from the most to the least cost-effective. Fig 6 is a list of optimization results for hybrid renewable energy charging station for 25 years project lifetime with FiT rates RM 0.813/kWh.

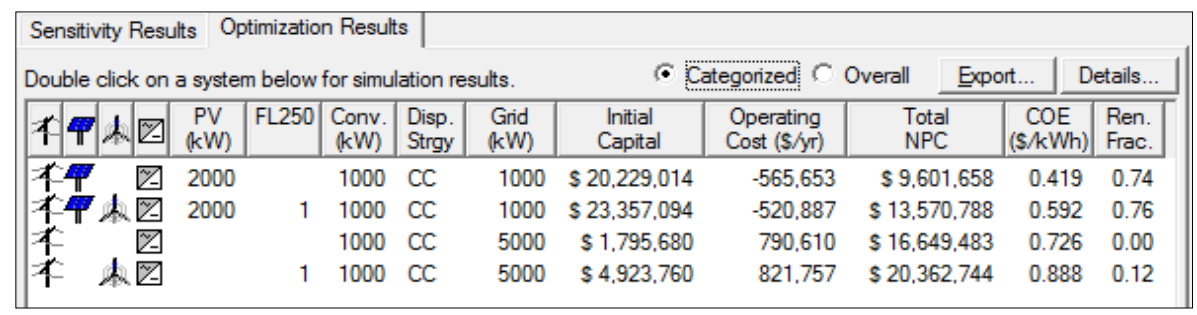

Fig. 6. Hybrid system optimization result. 
The result shows that the grid-PV system is the most feasible grid hybrid RE system to be developed with lowest NPC at RM 9,601,658 with cost of electricity (COE) is RM $0.419 / \mathrm{kWh}$. The $0.74 \mathrm{RE}$ fraction is produced from $2000 \mathrm{~kW}$ of PV with combination of $1000 \mathrm{~kW}$ converter and $1000 \mathrm{~kW}$ grid purchased. Meanwhile, grid-wind-PV system also feasible to be developed with addition of one unit wind turbine from grid-PV configuration. The NPC and COE for this system is RM 13,570,788 and RM $0.592 / \mathrm{kWh}$, respectively. It is noticeable that both grid-PV and grid-wind-PV system producing negative operating cost. The negative sign indicates both systems earn more income by selling excess electricity to the grid than purchasing electricity from the grid.

The existing system which is grid-only system becomes the third based on the NPC value at RM 16,649,483 with COE is RM $0.726 / \mathrm{kWh}$. This system might not invest much in capital cost since the system only needs to be connected to grid utility system with $1000 \mathrm{~kW}$ converters. The least optimal configuration is grid-wind system with a very high NPC which is RM 20,362,744 and the COE RM $0.888 / \mathrm{kWh}$. Since purchasing electricity from the grid is more cost-effective than using the wind turbine, the system chooses only one unit wind turbine and $5000 \mathrm{~kW}$ from the grid although the sizing range of wind turbine is set up to 10 units. The summary of all system performance at FiT rates RM $0.813 / \mathrm{kWh}$ are shown in Table 1.

Table 1. The performance of grid-only and grid-connected RE systems at FiT rates RM 0.813/kWh.

\begin{tabular}{|l|c|c|c|c|}
\hline \multirow{2}{*}{ Performance } & \multicolumn{4}{c|}{ Systems } \\
\cline { 2 - 5 } & $\begin{array}{c}\text { Grid-only } \\
\text { system }\end{array}$ & $\begin{array}{c}\text { Grid-PV } \\
\text { system }\end{array}$ & $\begin{array}{c}\text { Grid-wind- } \\
\text { PV system }\end{array}$ & $\begin{array}{c}\text { Grid-wind } \\
\text { system }\end{array}$ \\
\hline Grid purchase (kWh/yr) & $1,436,381$ & 918,103 & 890,243 & $1,393,448$ \\
\hline $\begin{array}{l}\text { Electrical production } \\
\text { (kWh/yr) }\end{array}$ & - & $2,609,669$ & $2,796,430$ & 186,761 \\
\hline Grid sales (kWh/yr) & - & $1,880,463$ & $2,016,457$ & 143,829 \\
\hline Total income (RM/yr) & - & $1,528,816.42$ & $1,639,379.54$ & $116,932.98$ \\
\hline Total emission (kg/yr) & 913,654 & $-612,138$ & $-716,362$ & 794,857 \\
\hline Payback (yr) & - & 13.2 & 14.2 & 42.1 \\
\hline
\end{tabular}

From the table, it is clearly that the dependency on the grid can be reduced when the grid is hybrid with RE sources as the grid purchase capacity is reduced for all three configurations. The electrical production by RE sources is highest for hybrid grid-wind-PV as two RE sources are used to generate electricity. As more electricity generated, more excess electricity can be sold to the grid as shown in grid sales. The total income is simply obtained by multiplying the grid sales with the FiT rate. Although the grid-wind-PV system is able to generate more income compared to grid-PV system, the cost of wind turbine is so expensive that contribute to higher NPC.

Since all systems are grid-connected, the emission still occurs. The negative total emissions occur for systems with negative operating cost which are grid-PV and grid-windPV system. This is because HOMER simply multiplies the net grid purchases by the emission factor for each pollutant. So, for configurations with grid purchase lower than grid sale, the net grid purchase is negative. As expected, the hybrid renewable energy sources reduced the pollutant emission compared to grid-only systems.

The payback period is the length of time it takes for a project to generate enough cash flow to pay back the initial investment. From equation (4) [28], the payback period of the system can be determined. This system project lifetime is 25 years. In Table 1 , the grid-PV system has shortest period to a return of investment with 13.2 years at rates RM $0.813 / \mathrm{kWh}$ 
followed by grid-wind-PV systems and grid-wind with 14.2 years and 42.1 years, respectively. However, the grid-wind system is still not being able to precede grid-only system even though the wind energy technology is promising energy sources in Terengganu [29]. Thus, to find the least FiT that can be used to get the most optimal hybrid grid-RE configuration, sensitivity analysis was done.

\subsection{Sensitivity analysis of hybrid renewable energy system}

In this analysis, the FiT rates of solar PV that have been implemented by SEDA in the previous years were used as sensitivity values which are $\{0.813,0.86,0.991,1.03,1.14$ and 1.24 \} in unit $\mathrm{RM} / \mathrm{kWh}$.

\subsubsection{NPC verses FiT rates}

The increments of the FiT rates generally reduce the NPC values as more income can be generated from selling electricity to the grid. This is clearly shown in Figure 8 for grid-PV and grid-wind-PV systems. The significant reductions occur in NPC value as the percentage of grid sales for both systems are above $60 \%$. However, only slight changes in NPC value for grid-wind system as the percentage of grid sale for this configuration is $11 \%$. The FiT doesn't affect the value of NPC for grid-only system as it only supplies energy to the load.

From Fig. 7, the minimal value of FiT rates in gaining profitable revenue is unknown for all three configurations as the points do not intersect with grid-only system. So, Figure 8 and Figure 9 are used to predict the minimal value of FiT for all configurations.

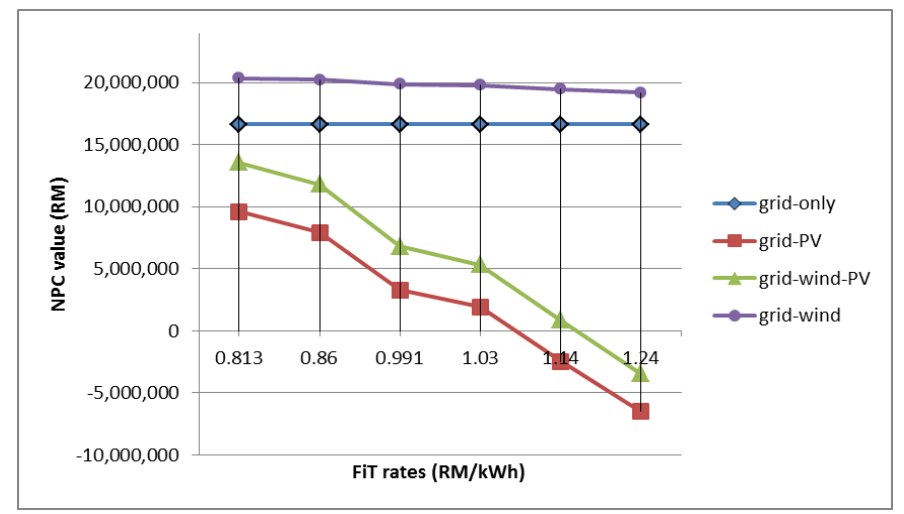

Fig. 7. FiT rates versus NPC value.

From Fig 8, the minimal FiT for grid-wind system is RM 2.20/kWh. From Fig 9, the minimal FiT for grid-wind-PV and grid-PV systems are RM 0.72/kWh and RM0.56/kWh, respectively. Above the values, the grid-RE systems are more optimal compared to the grid only system. 


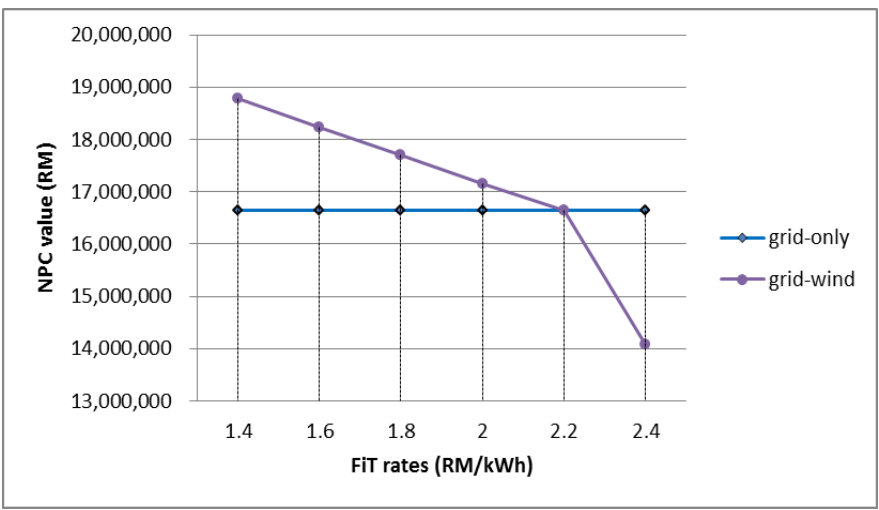

Fig. 8. Possible FiT rates for grid-wind system.

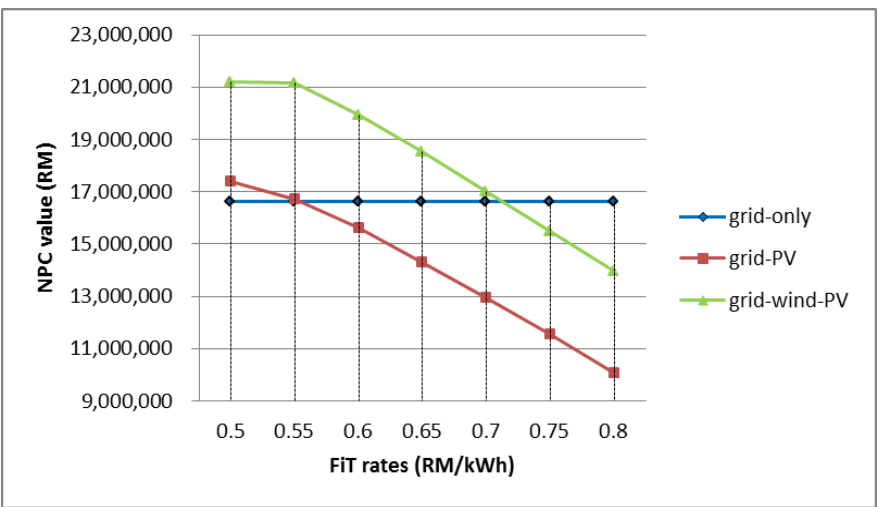

Fig. 9. Minimal FiT rates for grid-PV system and grid-wind-PV system.

\subsubsection{Emission of pollutants verses FiT rates}

Emission of pollutants do not effect directly with the FiT. If the size of PV remains the same for different FiT, the net grid purchase is also remaining the same. As the emissions of pollutants are obtained by multiplying the net grid purchase with the emission factor, the emissions also remain. However, with the changes in FiT, HOMER calculates that the optimal size of PV is $2500 \mathrm{~kW}$ for FiT RM 1.14/kWh and RM 1.24/kWh. As a result, grid sales for these FiT become higher and net grid purchases become more negative. So, the emission of pollutants also decrease for both grid-PV and grid-wind-PV systems as shown in Fig 10. However, no changes happened in the optimal size of wind turbine for grid-wind system, thus, the value of emission of pollutants for this configuration doesn't change with the FiT and remain at the same value as in Table 1.

\subsubsection{Payback period verses FiT rates}

Fig 11 shows the payback decrease with the increase of FiT. It is true as more income can be generated from selling electricity to the grid, the payback period becomes shorter. Since the grid-wind system produces the payback period longer than the project lifetime, it is not included in the results. 


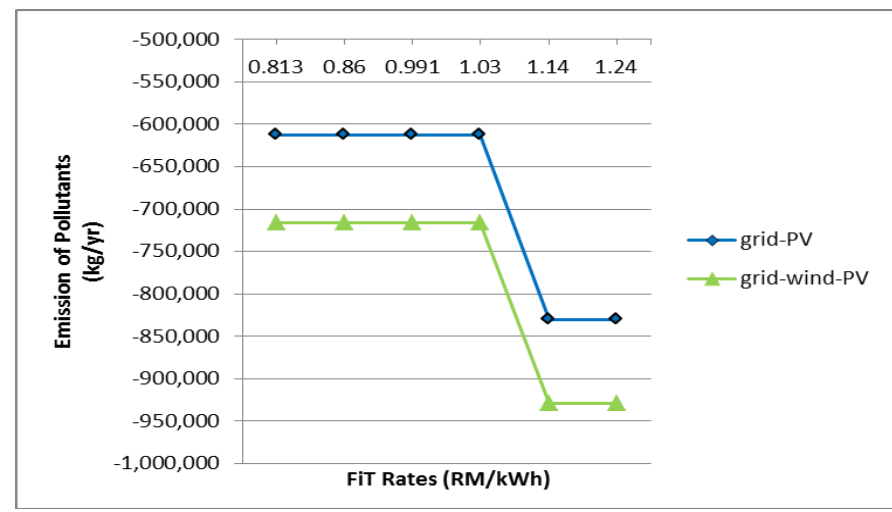

Fig. 10. FiT rates versus emission of pollutants.

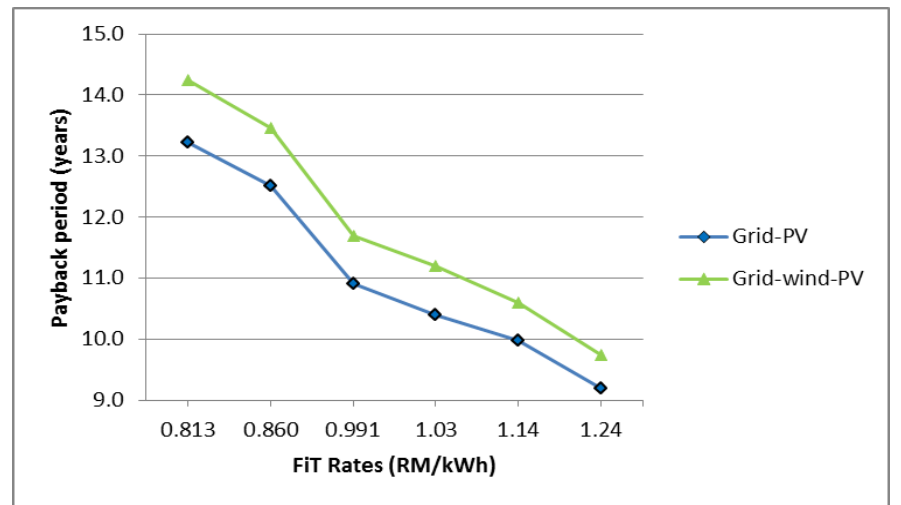

Fig. 11. FiT rates versus payback period.

\subsubsection{Malaysia subsidy scheme}

Government has allocated an amount of subsidy for the fishermen. Based on [12], in 2014, the amount of fuel subsidy received by the fishermen at KTU area was RM 1,228,325.70. However, from the results in Table 1, the most optimal system which is grid-PV system is able to generate RM 1,528,815/year, higher than the subsidy spent by the government. So, for long term investment, the development of the proposed system is more beneficial than fuel subsidy. Moreover, the fund in other sector such as education and medical sector can be raised when the subsidy is reduced.

\section{Conclusions}

From HOMER simulation, Kuala Terengganu has potential in developing RE system and the result of economic analysis with four different configurations which are the grid-only, grid-PV, grid-wind-PV and grid-wind systems have been presented. The grid-PV system is the most feasible configuration using the current FiT rates at RM 0.813/kWh. To encourage the use of PV, the FiT rate for the system should not be reduced below RM0.56/kWh. Since the wind turbine is expensive and the wind speed in the selected area is low, the FiT rate should be increased up to RM $2.20 / \mathrm{kWh}$ in order to get the benefit of the grid-wind and grid-wind-PV system. 


\section{References}

1. P. Suuronen, F. Chopin, C. Glass, S. Løkkeborg, Y. Matsushita, D. Queirolo, D. Rihan, Low impact and fuel efficient fishing-Looking beyond the horizon. Fisheries Research 119-120, 135-146 (2012)

2. M. Ferry, W. W. Nik, MFAhmad, F. Gaspersz, M. Manuputty, Comparative study of hybrid catamaran versus diesel monohull boat as ferry for short distance routes. Indonesian Journal of Naval Architecture 1, 29-36 (2013)

3. J. Nóbrega, T. C. Dan, Rubanenco, Electric propulsion applied for research vessel. Renewable Energy and Power Quality Journal, (2013)

4. J. V. a. C. Rast, "2015 Top markets report recreational transportation," A Market Assessment Tool for U.S. Exporters (International Trade Administration, U.S. Department of Commerce, 2015)

5. S. Minami, K. Koizumi, T. Hanada, N. Matsuda, K. Ishizu, J. Nishi, T. Fujiwara, Performance of a newly developed plug-in hybrid boat. Electric Vehicle Symposium and Exhibition (EVS27), 2013 World, 1-4 (2013)

6. Vítor Monteiro, J. C. Ferreira, J. L. Afonso, Smart battery charger for electric mobility in smart grids. $1^{\text {st }}$ International Conference on Smart Grids and Battery IT Systems, 1$6(2012)$

7. M. A. A. F. Yousif, E. Alfegi, N. Asim And K. Sopian, Simulation of hybrid PV-“3 phase grid" electric vehicle charging system. 7th International Conference on Renewable Energy Sources (RES '13), 310-315 (2013)

8. S. Mekhilef, M. Barimani, A. Safari, Z. Salam, Malaysia's renewable energy policies and programs with green aspects. Renewable and Sustainable Energy Reviews 40, 497504 (2014)

9. W. M. W. Muda, C. A. Fong, Simulation-based method to evaluate pv-wind hybrid renewable energy system in Terengganu. Energy and Sustainability V 186, 12 (2015)

10. R. Ali, I. Daut, S. Taib, A review on existing and future energy sources for electrical power generation in Malaysia. Renewable and Sustainable Energy Reviews 16, 40474055 (2012)

11. SEDA, Sustainable Energy Development Authority Malaysia Accessed on: $14^{\text {th }}$ August 2015

12. LKIM, Lembaga Kemajuan Ikan Malaysia. Accessed on: 16th May 2015

13. N. H. Sa'at, Social mobility among the coastal community: A case study in kuala terengganu. Kajian Malaysia 29, 95-123 (2011)

14. S. C. Chua, T. H. Oh, Review on Malaysia's national energy developments: Key policies, agencies, programmes and international involvements. Renewable and Sustainable Energy Reviews 14, 2916-2925 (2010)

15. Tenth Malaysia plan 2011-2015 (2010).

16. A. S. Abdullah, M. P. Abdullah, M. Y. Hassan, F. Hussin, Renewable energy costbenefit analysis under Malaysian feed-in-tariff. Research and Development (SCOReD), 2012 IEEE Student Conference, 160-165 (2012)

17. T. Khatib, A. Mohamed, K. Sopian, Optimization of a PV/wind micro-grid for rural housing electrification using a hybrid iterative/genetic algorithm: Case study of Kuala Terengganu, Malaysia. Journal of Energy and Buildings 47, 321-331 (2012)

18. N. A. b. A. Razak, M. M. bin Othman, I. Musirin, Optimal sizing and operational strategy of hybrid renewable energy system using homer. Power Engineering and Optimization Conference (PEOCO), 2010 4th International, 495-501 (2010)

19. T. Khatib, K. Sopian, H. A. Kazem, Actual performance and characteristic of a grid connected photovoltaic power system in the tropics: A short term evaluation. Energy Conversion and Management 71, 115-119 (2013) 
20. N. A. S. Salleh, W. M. W. Muda, S. S. Abdullah, Feasibility study of optimization and economic analysis for grid-connected renewable energy electric boat charging station in Kuala Terengganu. 2015 IEEE Conference on Energy Conversion (CENCON), 510515 (2015)

21. R. N. S. R. Mukhtaruddin, H. A. Rahman, M. Y. Hassan, Economic analysis of gridconnected hybrid photovoltaic-wind system in Malaysia. Clean Electrical Power (ICCEP), 2013 International Conference, 577-583 (2013)

22. UniSZA, Weather Station. Accessed on: 10th February 2015

23. M. S. Ngan, C. W. Tan, Assessment of economic viability for PV/wind/diesel hybrid energy system in southern Peninsular Malaysia. Renewable and Sustainable Energy Reviews 16, 634-647 (2012)

24. TNB, Tenaga Nasional Berhad. Accessed on: 30th March 2015

25. R. Hara, H. Kita, T. Tanabe, H. Sugihara, A. Kuwayama, S. Miwa, Testing the technologies. IEEE Power and Energy Magazine 7, 77-85 (2009)

26. Global economics research. Accessed on: 22nd December 2015

27. MEIH, Department of Statistic Malaysia: Electricity Generation. Accessed on: 6th May 2015

28. M. M. Gilbert, in Renewable and efficient electric power systems. (John Wiley and Sons, New York, 2004), chap. Chapter 5: Economics of Distributed Resources, pp. 240-254.

29. A. Albani, M. Z. Ibrahim, Y. K.H., The feasibility study of offshore wind energy potential in Kijal, Malaysia: the new alternative energy source exploration in Malaysia. Journal of Energy Exploration \& Exploitation 32, 329-344 (2014) 